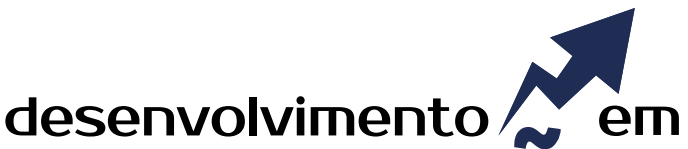 QUESTÃO
}

\section{O Programa Nacional de Fortalecimento da Agricultura Familiar no Brasil Análise da Evolução e Distribuição Entre 1999 e 2017}

http://dx.doi.org/10.21527/2237-6453.2020.50.109-128

Recebido em: $14 / 11 / 2018$

Aceito em: 5/8/2019

\author{
Alessandra Troian, ${ }^{1}$ Edenilson Tafernaberry Lencina Machado ${ }^{2}$
}

\begin{abstract}
RESUMO
O Estado brasileiro legitimou tardiamente a agricultura familiar como categoria social, simultaneamente com a constituição do Programa Nacional de Fortalecimento da Agricultura Familiar (Pronaf), em meados da década de 90 do século 20. Desde sua criação, o Pronaf vem passando por transformações visando a ampliar as linhas de crédito e o público-alvo. Nesse sentido, o presente estudo objetiva analisar a evolução e a distribuição dos recursos do Programa Nacional de Fortalecimento da Agricultura Familiar entre as regiões brasileiras no período de 1999 a 2017. Especificamente, buscou-se: a) apresentar o Programa; b) identificar o valor de recursos distribuídos entre as regiões brasileiras e c) elencar os principais entraves e desafios do Programa. Metodologicamente a pesquisa classifica-se como qualitativa, a partir do método dedutivo. Buscaram-se dados secundários no Banco Central do Brasil (BCB). Também foi utilizada a pesquisa bibliográfica. Como principais resultados destaca-se a desigualdade e concentração na distribuição do crédito, o qual se agrupou na Região Sul entre os anos 1999 e 2002. Entre 2003 e 2006 os recursos foram mais bem distribuídos e a Região Sul diminuiu sua participação com aumento da participação das Regiões Nordeste, Sudeste e Norte. A partir de 2007 ocorreu reconcentração dos recursos na Região Sul, o Programa voltou a promover a agricultura moderna, sendo acessado basicamente por produtores de commodities em regiões capitalizadas. Como limitações do Pronaf destaca-se a seletividade em favor de agricultores capitalizados, produtores de commodities, a concentração regional de crédito e o baixo acesso de unidades familiares mais empobrecidas.
\end{abstract}

Palavras-chave: Política pública. Agricultura familiar. Crédito. Desenvolvimento rural.

THE NATIONAL PROGRAM FOR STRENGTHENING FAMILY AGRICULTURE IN BRAZIL: ANALYSIS OF EVOLUTION AND CONCENTRATION BETWEEN 1999 AND 2017

\begin{abstract}
The Brazilian State legitimated late family farming as a social category, simultaneously with the constitution of the National Program for Strengthening Family Agriculture (Pronaf) in the mid-1990s. Since its inception, Pronaf has passing transformations aimed at credit and the target audience. The present study intends to analyze the evolution and distribution of the resources of the National Program for Strengthening Family Farming between the Brazilian regions from 1999 to 2017. Specifically, it was sought: a) present the program; b) identify the value of resources distributed among the Brazilian regions; and c) highlighting the main obstacles and challenges of the program. Methodologically the research is classified as qualitative, from the deductive method. Secondary data were sought from the Central Bank of Brazil (BCB). Bibliographic research was also used. The main results highlight the inequality and concentration in the distribution of credit, which was grouped in the Southern Region between 1999 and 2002. Between 2003 and 2006 resources were better distributed and the South Region decreased its participation with increased participation of the Northeast, Southeast and North regions. Since 2007, resources have been re-concentrated in the Southern Region. The program has again promoted modern agriculture, being accessed basically by commodity producers in capitalized regions. Pronaf limitations include selectivity in favor of capitalized farmers, commodity producers, regional concentration of credit and low access to more impoverished households.
\end{abstract}

Keywords: Public policy. Family farming. Credit. Rural development.

\footnotetext{
${ }^{1}$ Doutora em Desenvolvimento Rural pela Universidade Federal do Rio Grande do Sul (UFRGS). Professora da Universidade Federal do Pampa (Unipampa), campus de Santana do Livramento. alessandratroian@unipampa.edu.br

${ }^{2}$ Bacharel em Ciências Econômicas pela Universidade Federal do Pampa (Unipampa), campus de Santana do Livramento. edenilsonlencina@ hotmail.com
} 
Historicamente o crédito rural no Brasil, foi incapaz de atender à demanda dos agricultores familiares. Com a consolidação da Constituição de 1988, surgem os primeiros movimentos sociais rurais, os quais reivindicavam a elaboração de políticas mais específicas de desenvolvimento rural para a agricultura brasileira. Nos anos 90 os movimentos foram determinantes para modificar o rumo das políticas de desenvolvimento rural, ocasião em que as ações dos trabalhadores rurais passam a conduzir suas reivindicações para a chamada "reconversão e reestruturação produtiva" dos agricultores familiares, categoria social até então não reconhecida pelo Estado (SCHNEIDER et al., 2004).

Com a pressão imposta pelos movimentos sociais, criou-se no ano de 1994 o Programa de Valorização da Pequena Produção Rural (Provape), a primeira resposta do Estado para atender aos movimentos sociais rurais na época. O Provape voltava-se para o financiamento do custeio da safra, com o diferencial de ofertar crédito para os pequenos produtores rurais. Um ano após a aprovação do Provape, o programa passa por modificações, principalmente na concepção e na área de atuação (MATTEI, 2005). As alterações no Provape resultaram na criação, em 1996, do Programa Nacional de Fortalecimento da Agricultura Familiar (Pronaf), a primeira política pública para atender especificamente à agricultura familiar brasileira.

No Brasil, a criação do Pronaf deu-se em um período em que o país passava por sérias dificuldades no acesso ao crédito. Os agricultores, principalmente os familiares, estavam sem estímulo para permanecer no campo porque não existia política pública para a categoria e, também, pela falta de crédito na primeira metade dos anos $90-$ o único disponível tinha um custo muito elevado (GUANZIROLI, 2007). Desse modo, o Pronaf emerge como uma resposta do Estado, tendo como principal finalidade fornecer crédito agrícola de auxílio aos agricultores familiares (SCHNEIDER et al., 2004).

Após pouco mais de 20 anos de atuação e uma série de estudos realizados, ainda tem-se algumas questões a respeito do Programa Nacional de Fortalecimento da Agricultura Familiar que carecem de respostas. Assim, o presente estudo visa a analisar a evolução e a distribuição dos recursos do Programa Nacional de Fortalecimento da Agricultura Familiar entre as regiões brasileiras no período de 1999 a 2017. A pesquisa tem ainda objetivos específicos, a saber: a) apresentar o Programa Nacional de Fortalecimento da Agricultura Familiar e suas condicionalidades; b) identificar o valor de recursos distribuídos entre as regiões brasileiras e c) elencar os principais entraves e desafios do programa.

Para tanto, metodologicamente a pesquisa realizou-se a partir do método dedutivo, por meio da pesquisa bibliográfica e análise de dados secundários, disponibilizados pelo Banco Central do Brasil. Visando a dar suporte teórico à pesquisa, o item a seguir fará um breve resgate acerca da agricultura familiar, suas características e especificidades, bem como discutirá sobre o Programa Nacional de Fortalecimento da Agricultura Familiar.

\section{AGRICULTURA FAMILIAR E DESENVOLVIMENTO RURAL NO BRASIL}

A agricultura familiar sempre se fez presente na sociedade brasileira, desenvolvendo as primeiras atividades agropecuárias. Apesar de vir se transformando no decorrer dos séculos, a agricultura familiar vem impedindo que ocorra seu desaparecimento 
diante das outras formas de agricultura, sem desfazer-se de sua característica principal, a produção de alimentos para o sustento da família, vendendo o excedente (BRUMER et al., 1997).

No Brasil, as dificuldades enfrentadas pela agricultura familiar no campo e as especificidades do setor nunca foram alvo de políticas públicas. As transformações que ocorreram na agricultura brasileira nas décadas de 60, 70 e 80 não estavam sendo favoráveis ao desenvolvimento da agricultura familiar, pois a atuação do Estado como empreendedor do desenvolvimento rural fomentava a extinção da pequena agricultura em prol dos setores mais capitalizados do país, voltados ao mercado internacional (BUAlNAIN; ROMEIRO; GUANZIROLI, 2003).

A baixa competitividade da propriedade familiar diante o processo de modernização da agricultura fez com que parte dos agricultores familiares vendessem suas terras para se arriscarem nos centros urbanos ou permanecerem no campo, obrigados a conviver em situações de miséria rural desamparados pelas políticas excludentes da época (DEL GROSSI; SILVA, 2002).

Posteriormente, com a promulgação da Constituição Federal de 1988, tiveram início as primeiras reivindicações dos trabalhadores rurais, as quais se intensificaram e ganharam destaque apenas na década de 90, quando a expressão "agricultura familiar" emerge (SCHNEIDER, 2003; SCHNEIDER et al., 2004). Nesse período, o que contribuiu para que a expressão "agricultura familiar" fosse utilizada com maior frequência foram as reivindicações dos movimentos sociais rurais e demais agentes que participaram ativamente na luta pela introdução de uma política pública voltada especificamente para atender o agricultor familiar (MATTEI, 2005).Por esse motivo a década de 90 é vista como um processo de abertura de novas possibilidades e de inserção mercantil dos agricultores familiares. A conquista formalizou-se a partir da criação do Programa Nacional de Fortalecimento da Agricultura Familiar, em 1996, o qual transformou o modelo agrícola brasileiro prevalecente com inclusão econômica, social e política dos agricultores familiares (SCHNEIDER et al., 2004).

Diante desse breve contexto, devido à importância do reconhecimento conferido à agricultura familiar e a inserção do Pronaf na política agrícola brasileira, a academia vem desenvolvendo uma série de pesquisas, resultando em diversas definições e caracterizações acerca da expressão "agricultura familiar", as quais podem ser vistas no Quadro 1 a seguir.

Quadro 1 - Distintas definições para a expressão agricultura familiar e respectivas autorias

\begin{tabular}{|c|c|}
\hline Definições para a expressão agricultura familiar & Autoria \\
\hline $\begin{array}{c}\text { Caracterizada como aquela em que a família exerce o trabalho produtivo } \\
\text { ao mesmo tempo em que é proprietária dos meios de produção. Tem uma } \\
\text { estrutura produtiva que envolve família-produção-trabalho e todas as estra- } \\
\text { tégias definidas pela família tendem a assegurar sua sobrevivência imediata } \\
\text { e garantir a reprodução das gerações subsequentes. }\end{array}$ & Wanderley \\
\hline $\begin{array}{c}\text { Unidade de produção com condições extremamente distintas, variadas e } \\
\text { assemelhadas. Grupo social não homogêneo, que tem excêntrica compe- } \\
\text { tência de adaptação. }\end{array}$ & Lamarche \\
\hline
\end{tabular}




\begin{tabular}{|c|c|}
\hline $\begin{array}{l}\text { Não se enquadra em um modelo único e envolve aspectos culturais no } \\
\text { modo de vida e como se associa às atividades econômicas. Associam as } \\
\text { relações familiares às atividades produtivas e têm vocação em adaptar-se a } \\
\text { situações regionais peculiares, incorporando e adaptando seu modo de pro- } \\
\text { dução às características locais. }\end{array}$ & Carneiro (1997) \\
\hline $\begin{array}{l}\text { Aquele que pratica atividades no meio rural atendendo basicamente às } \\
\text { seguintes condições: os afazeres no espaço produtivo ser praticado predo- } \\
\text { minantemente pelo produtor e família; ou seja, a mão de obra familiar ser } \\
\text { maior ao trabalho contratado, e a extensão do espaço produtivo estar den- } \\
\text { tro de uma área determinada especificamente para cada região do país. }\end{array}$ & $\begin{array}{l}\text { Guanziroli e } \\
\text { Cardim (2000) }\end{array}$ \\
\hline $\begin{array}{l}\text { As formas de organização produtiva adotadas vão além da produção/renta- } \\
\text { bilidade econômica, levando em consideração as necessidades e objetivos } \\
\text { da família. }\end{array}$ & Carmo (2000) \\
\hline $\begin{array}{l}\text { Unidades constituídas por grupos domésticos que realizam seus trabalhos } \\
\text { em regime de economia familiar, unidos por laços parentais e consanguí- } \\
\text { neos. }\end{array}$ & $\begin{array}{l}\text { Schneider } \\
\text { (2006) }\end{array}$ \\
\hline $\begin{array}{l}\text { Agricultores que praticam atividades no meio rural, atendendo, simultanea- } \\
\text { mente, aos seguintes requisitos: “I - não detenha, a qualquer título, área } \\
\text { maior do que } 4 \text { (quatro) módulos fiscais; II - utilize predominantemente } \\
\text { mão de obra da própria família nas atividades econômicas do seu estabe- } \\
\text { lecimento ou empreendimento; III - tenha percentual mínimo da renda } \\
\text { familiar originada de atividades econômicas do seu estabelecimento ou em- } \\
\text { preendimento, na forma definida pelo poder Executivo (Redação dada pela } \\
\text { Lei no } 12.512, \text { de 2011); IV - dirija seu estabelecimento ou empreendimen- } \\
\text { to com sua família". }\end{array}$ & $\begin{array}{l}\text { Brasil (2006, } \\
\quad \text { art. 3) }\end{array}$ \\
\hline $\begin{array}{l}\text { Conduta influente da família na estrutura de organização da reprodução so- } \\
\text { cial, por meio da elaboração de estratégias familiares e individuais que influi } \\
\text { na transferência do patrimônio material e cultural. } \\
\text { Modo de exploração agrícola familiar em que a propriedade e trabalho en- } \\
\text { contram-se ligados à família. }\end{array}$ & $\begin{array}{c}\text { Savoldi e Cunha } \\
\text { (2010) }\end{array}$ \\
\hline
\end{tabular}

Fonte: Elaborado pelos autores.

A partir das informações presentes no Quadro 1, percebe-se que nos últimos anos houve avanços substanciais no âmbito dos estudos rurais sobre a produção familiar. 0 principal deles diz respeito ao reconhecimento da diversidade econômica e heterogeneidade social do grupo, caraterizado pelo número expressivo de estabelecimentos instalados no país, presentes em todas as regiões brasileiras, com diferentes condições de terras, condição do produtor, tipo de atividade. Também se destaca o reconhecimento da agricultura familiar, pelos estudiosos, organizações sociais e gestores governamentais como uma categoria social diversa e heterogênea (SCHNEIDER, 2006; SCHNEIDER; CASSOL, 2014).

A partir da formulação do Pronaf a agricultura familiar passou a ser conhecida socialmente e legitimada pelo Estado. Sendo assim, o programa instituído por meio do Decreto no. 1.946, da Presidência da República, se propôs a promover a criação de incentivos para a ampliação da agricultura familiar no Brasil, para assim estimular o desenvolvimento rural sustentável (MATTEI, 2014b; SCHNEIDER et al., 2004). Para alcançar o objetivo o Programa foi estruturado como uma política de crédito agrícola e auxílio institucional voltado especificamente para os agricultores familiares, para que estes 
fossem introduzidos na economia brasileira como uma classe social produtiva. Desse modo, o Programa passaria a promover o aumento de produtividade, a diversificação de cultivos, emprego e renda (BRASIL, 1996; SCHNEIDER et al., 2004).

O crédito fornecido pelo Programa serviu como um estímulo para a permanência do agricultor familiar no campo, possibilitou acesso ao financiamento para o custeio da safra, o qual o auxilia na compra de máquinas e equipamentos necessários para o plantio. Dessa maneira, foi possível o agricultor familiar garantir o pagamento do financiamento por meio da renda obtida de sua própria produção (GRISA; SCHNEIDER, 2014; MATTEI, 2014b).

Pretendendo aumentar o número de agricultores familiares vinculados ao Programa, este passou por diversas modificações desde a sua criação, principalmente na estrutura. As primeiras modificações que houve correspondem ao período entre 1996 e 1999, momento em que ocorreu uma redução progressiva das taxas de juros, o que acabou provocando leves adulterações nos regulamentos de funcionamento do Programa (MATTEI, 2014a). As modificações ocorridas entre 1999 e 2008 foram em relação aos grupos de agricultores. A partir da Resolução no. 2.629 de 1999, os agricultores familiares passaram a ser classificados em grupos $A, B, C$ e D, de acordo com a renda e condição socioeconômica (MATTEI, 2014a). Os produtores rurais que se enquadrassem nos grupos estabelecidos na resolução no. 2.629, comprovados mediante declaração de aptidão ao programa (BRASIL, 1999), passaram a ser os beneficiários do Programa.

Visando a apresentar a classificação do programa de crédito para os agricultores familiares, o Quadro 2, a seguir, apresenta os grupos que compõem o Pronaf e a sua destinação.

Quadro 2 - Classificação dos agricultores familiares por grupos

\begin{tabular}{|c|c|}
\hline $\begin{array}{c}\text { Classificação dos agricultores familiares por } \\
\text { grupos em 1999: ano de criação dos grupos de } \\
\text { beneficiários }\end{array}$ & $\begin{array}{c}\text { Classificação dos agricultores por grupos } \\
\text { na safra } 2016 / 2017\end{array}$ \\
\hline $\begin{array}{c}\text { Grupo A - Agricultores assentados da reforma } \\
\text { agrária que, com a extinção do Programa Espe- } \\
\text { cial de Crédito para a Reforma Agrária (Procera), } \\
\text { passaram a ser atendidos pelo Pronaf. }\end{array}$ & \multirow{5}{*}{ 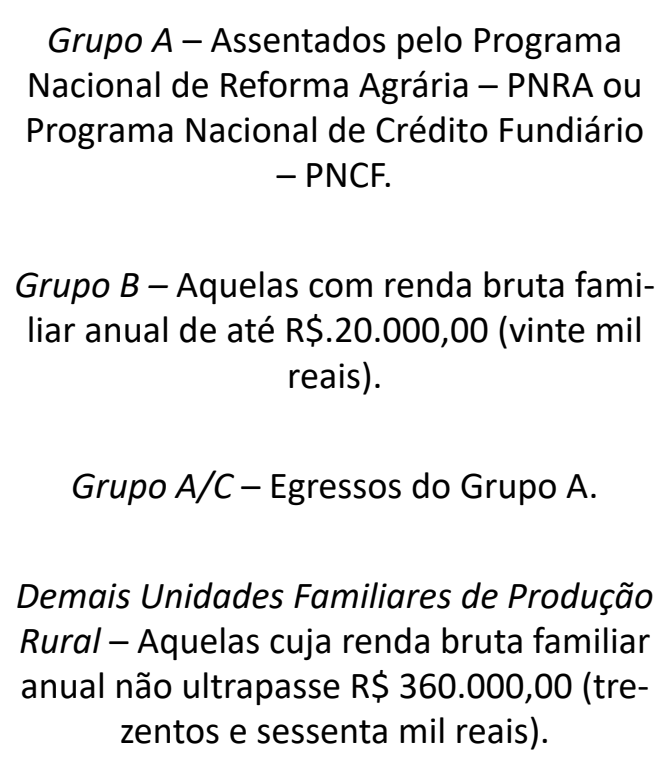 } \\
\hline $\begin{array}{c}\text { Grupo } B \text { - Agricultores familiares e trabalhadores } \\
\text { rurais que obtêm renda bruta anual familiar de } \\
\text { até } R \$ 1.500,00 \text {, excluídos os proventos de apo- } \\
\text { sentadoria rural. }\end{array}$ & \\
\hline $\begin{array}{c}\text { Grupo } C \text { - Agricultores familiares e trabalhadores } \\
\text { rurais que obtêm renda bruta anual familiar de } \\
R \$ 1.500,00 \text { até } R \$ 8.000,00 .\end{array}$ & \\
\hline $\begin{array}{c}\text { Grupo } D \text { - Agricultores familiares e trabalhadores } \\
\text { rurais que obtêm renda bruta anual familiar de } \\
\operatorname{R} \$ 8.000,00 \text { até } R \$ 27.500,00\end{array}$ & \\
\hline $\begin{array}{l}\text { Grupo } E^{3}-\text { Agricultores com renda bruta anual } \\
\text { entre } R \$ 40.000,00 \text { e } \mathrm{R} \$ 60.000,00 \text {. }\end{array}$ & \\
\hline
\end{tabular}

Fonte: Elaboração própria, baseado na Resolução no 2.629/99 (BRASIL, 1999), na Resolução no 3.206/04 (BRASIL, 2004), em Aquino e Schneider (2015) e Brasil (2017).

\footnotetext{
${ }^{3}$ Grupo E: Criado em 2004 por meio da resolução 3.206/04, o Pronaf passa a atender aos agricultores familiares intitulados como a "Classe Média Rural" (BRASIL, 2004; BIANCHINI, 2015).
} 
Desde sua criação o Pronaf vem progredindo, constituindo-se como a principal política pública de auxílio à agricultura familiar no meio rural brasileiro (AQUINO; SCHNEIDER, 2015). O Programa criou várias linhas de crédito, ampliou o número de agricultores beneficiários, aumentou o crédito e fomentou a institucionalização de alguns programas de garantia ligados a ele (CONTI; ROITMAN, 2011), porém o processo de evolução do Pronaf é caracterizado por avanços e ambiguidades (AQUINO; SCHNEIDER, 2015).

\section{METODOLOGIA}

Com o objetivo de analisar a evolução e a distribuição dos recursos do Programa Nacional de Fortalecimento da Agricultura Familiar entre as regiões brasileiras no período de 1999 a 2017, a pesquisa baseia-se no método dedutivo. De acordo com Wollenhaupt (2004), o método dedutivo consiste no raciocínio que parte do geral para chegar ao particular. Ou seja, a dedução trata de tirar uma verdade particular de uma verdade geral na qual ela está subentendida.

As técnicas de pesquisa utilizadas foram a revisão bibliográfica e a coleta e análise de dados secundários. A pesquisa bibliográfica, segundo Gil (2012), é desenvolvida a partir de material já elaborado, constituído principalmente por livros e artigos científicos. Para tanto, foi realizada uma revisão bibliográfica a partir de relatórios de pesquisas, artigos científicos, livros, entre outros materiais publicados acerca do tema da agricultura familiar.

Já na etapa de coleta e análise dos dados secundários, foram acessados os dados disponibilizados pelo Banco Central do Brasil, correspondentes ao período de 1999 a 2017. Os dados estão disponibilizados em duas plataformas diferentes: de 1999 a 2012 estão disponíveis no Anuário Estatístico do Crédito Rural, e de 2013 a 2017 estão disponibilizados na Matriz de Dados do Crédito Rural. Destaca-se que foi realizada a correção monetária dos valores por meio do corretor de valores do Banco Central do Brasil com a utilização do Índice Geral de Preços-Disponibilidade Interna (IGP-DI) ${ }^{4}$ - base janeiro de 2018. Segundo Hair (2005), dados secundários são aqueles que já foram publicados com outra finalidade.

A análise dos dados deu-se pelo método analítico, que objetiva organizar os dados para responder às questões do estudo (GERHARDT; SILVEIRA, 2009). Assim, os dados coletados foram representados de forma gráfica e proporcional, os quais serão apresentados no item a seguir, que é de análise e discussão dos resultados.

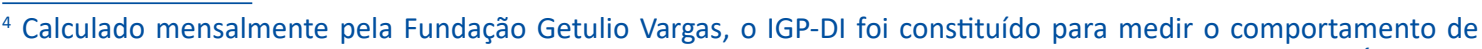
preços em geral da economia brasileira. Basicamente, é uma média aritmética, ponderada dos índices: Índice de Preços no Atacado (IPA), Índice de Preços ao Consumidor (IPC) e o Índice Nacional da Construção Civil (INCC). O DI ou Disponibilidade Interna é a consideração das variações de preços que afetam diretamente as atividades econômicas localizadas no território brasileiro (BANCO CENTRAL DO BRASIL, 2017b).
} 


\section{PROGRAMA NACIONAL DE FORTALECIMENTO DA AGRICULTURA FAMILIAR: EVOLUÇÃO E CONCENTRAÇÃO}

Nesta seção será apresentada a análise dos resultados obtidos no presente estudo. Inicia-se expondo a evolução dos recursos distribuídos pelo Pronaf entre as regiões brasileiras no período em questão. Na sequência discorre-se acerca das linhas de crédito do Programa.

\section{Recursos Distribuídos pelo Pronaf entre as Regiões Brasileiras}

Os valores aplicados pelo Pronaf de 1999 a 2017 sofreram constantes alterações, relacionadas ao tipo de política macroeconômica adotada pelos governos em termos de políticas públicas para o meio rural brasileiro (AQUINO, 2009; COSTA; SIMIONATTO, 2013). O Gráfico 1 é uma representação do número de contratos e dos valores repassados pelo Programa no período de 1999 a 2017. Pode-se visualizar o aumento do valor transferido no decorrer dos anos e oscilação no número de contratos firmados.

Gráfico 1 - Número de contratos e montante do crédito repassado pelo Pronaf no período de 1999 a 2017

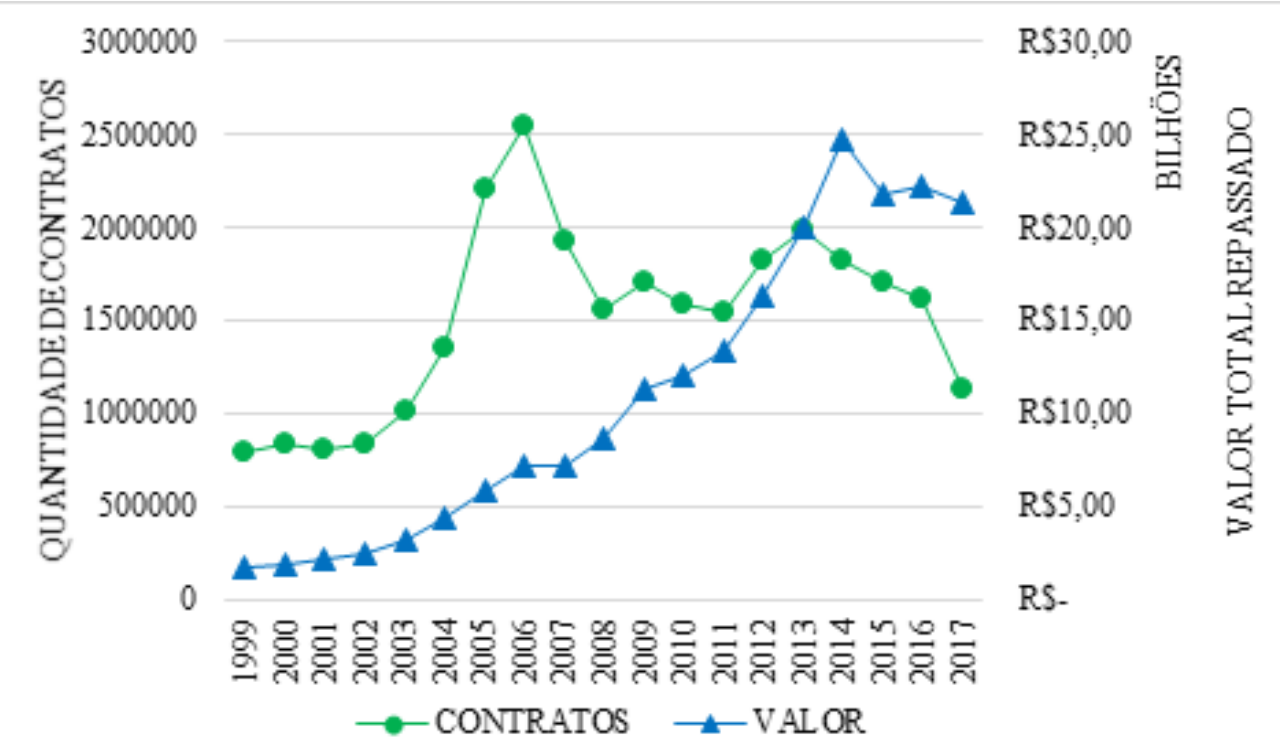

Fonte: Elaboração própria com base nos dados do Banco Central do Brasil (2017a).

No período de análise aumentaram tanto o montante de recursos financeiros disponibilizados pelo Pronaf quanto o número de beneficiários. O aumento corresponde a $43,48 \%$ no número de contratos e $1.097,25 \%$ no valor investido no Programa. Do ponto de vista dos contratos, nota-se uma fase de crescimento expressivo entre 2003 e 2006, associado principalmente às mudanças institucionais realizadas no primeiro mandato do então presidente da República Luiz Inácio Lula da Silva (2003-2007) (MATTEl et al., 2007; AQUINO; SCHNEIDER, 2015).

A partir do momento em que Luiz Inácio Lula da Silva torna-se presidente da República, em 2003, o governo passou a fomentar a modernização da agricultura brasileira tendo em vista a transformação dos processos e a expansão da produção. Em seu primeiro mandato reformulou a estrutura do Pronaf a fim de expandi-lo e aperfeiçoá-lo; 
realizou a ampliação dos limites de crédito; incluiu novos grupos de prováveis beneficiários; promoveu modificações nas porcentagens mínimas da renda familiar que precisaria originar-se da exploração agropecuária e não agropecuária; realizou a expansão de novas linhas de créditos de investimento e, por fim, como já mencionado, criou Grupo "E", entre outros (COSTA; SIMIONATTO, 2013).

Todas as transformações realizadas fizeram com que atualmente o Programa aplicasse mais de $\mathrm{R} \$ 160$ bilhões em mais de 26 milhões de contratos, em modalidades distintas, para diferentes regiões e grupos de agricultores familiares, financiando tanto a agricultura familiar mais estruturada quanto aquela menos capitalizada (BIANCHINI, 2015). Conforme Aquino e Schneider (2015), a evolução do crédito demonstra ter um comportamento crescente no período de análise, apresentando apenas decréscimo nos anos de 2007 e 2015 em relação aos anos 2006 e 2014. Pode-se constatar que o crédito desembolsado pelo Programa teve movimento ascendente principalmente entre $2002 \mathrm{e}$ 2014, mostrando uma mudança em comparação aos anos anteriores, dado que a partir dos anos 2000 até o final do governo de Fernando Henrique Cardoso o programa demonstra certa paralisação na liberação de recursos.

Gráfico 2 - Valor total repassado pelo Pronaf* no período de 1999 a 2017

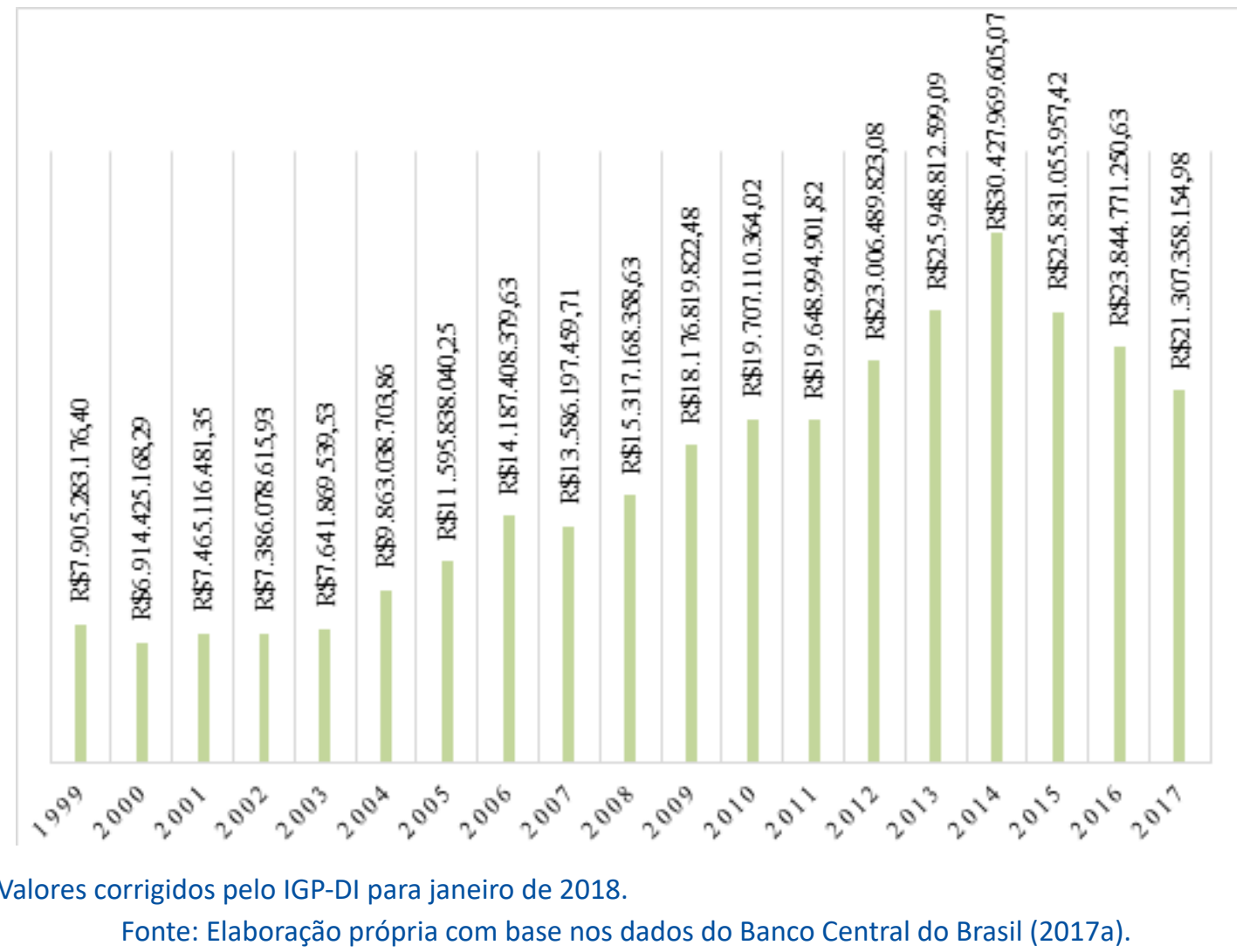

No que se refere aos valores liberados para o Pronaf no período entre 1999 e 2017, é possível visualizar no Gráfico 2 que no período inicial há certa estagnação, havendo uma elevação notável após o ano de 2003. Os valores apresentados no Gráfico 2 evidenciam as oscilações nos valores liberados pelo Programa entre 1999 e 2003, expondo um período de estagnação do crescimento do crédito, situando-se na faixa de R\$ 7 bilhões, além de apresentar leves reduções no crédito nos anos 2000 e 2002. 
Durante o primeiro governo do presidente Luiz Inácio Lula da Silva (2003-2007) há a presença dos agricultores familiares nas negociações e execução dos Planos Safra, ${ }^{5}$ e isso refletiu em resultados positivos tanto para os beneficiários quanto para o crescimento do programa (BIANCHINI, 2015). O Pronaf ganhou maior visibilidade, tornando-se uma política agrícola crescente, apresentando altos volumes de liberação de crédito, registrando uma redução no ano de 2007 de R\$ 601 milhões e no ano de 2011 de $R \$ 58$ milhões. É no governo da presidente da República Dilma Vana Rousseff ${ }^{6}$ (20112016), entretanto, que o Pronaf é marcado pelas oscilações. Nesse governo, o Programa chegou a conceder aos seus beneficiários mais de $R \$ 30$ bilhões em 2014, o máximo distribuído em toda a sua história. Nos anos posteriores, contudo, os valores concedidos sofrem reduções relevantes, chegando a contabilizar uma perda no seu orçamento de R\$ 4,5 bilhões no ano de 2015, R\$ 1,9 bilhão no ano de 2016 e R\$ 2,5 bilhões em 2017. Essas reduções já sinalizam um possível retrocesso do programa, o que pode acarretar em um retorno negativo ao agricultor familiar.

A redução dos recursos pode estar diretamente interligada à própria recessão econômica que o Brasil vivenciou no ano de 2015. Nesse mesmo ano, para o enfrentamento da crise econômica, foi instituída pelo governo Dilma uma política fiscal contracionista, entendida como necessária para retomar a confiança dos agentes e promover a recuperação da economia. Em 2016 o Brasil ainda sofria com o retrocesso econômico e propagação da crise política, dois fatores que praticamente paralisaram as ações do governo. O desafio do governo foi estabelecer um novo ajuste fiscal (PAULA; PIRES, 2017). Destarte, pode-se afirmar que a recessão econômica brasileira influiu diretamente na própria recessão dos recursos liberados pelo Pronaf, fazendo com que nos anos de 2015, 2016 e 2017 p Programa sofresse perdas jamais enfrentadas no histórico do Programa.

O Gráfico 3, apresentado a seguir, destaca o valor de recursos distribuídos entre as regiões brasileiras entre 1999 e 2017, enquanto o Gráfico 4 traz o montante total de recursos distribuídos pelo Programa entre as regiões brasileiras no mesmo período.

\footnotetext{
${ }^{5}$ Plano Safra é um conjunto de ações para o fortalecimento da agricultura familiar. "São ações para oferecer segurança jurídica da terra, com titulação e regularização fundiária; seguro da produção; ações para o Semiárido; Assistência Técnica e Extensão Rural; entre outros" (MDA, 2017, p. 2).

${ }^{6}$ Filiada ao Partido dos Trabalhadores (PT). Coligação: Partido do Movimento Democrático Brasileiro (PMDB), Partido Democrático Trabalhista (PDT), Partido Comunista do Brasil (PCdoB), Partido Socialista Brasileiro (PSB), Partido da República (PR), Partido Republicano Brasileiro (PRB), Partido Social Cristão (PSC), Partido Trabalhista Cristão (PTC) e Partido Trabalhista Nacional (PTN).
} 
Gráfico 3 - Distribuição regional do crédito do Pronaf de 1999 a 2017

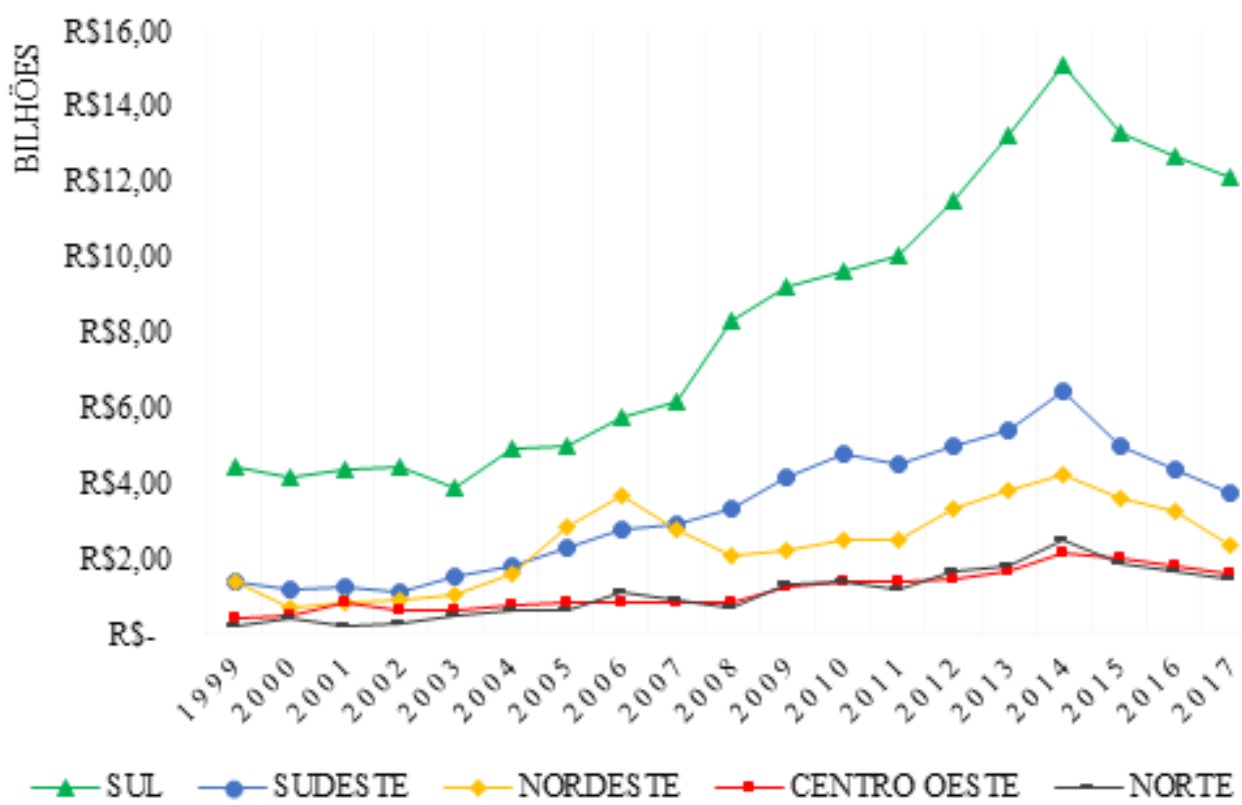

*Valores corrigidos pelo IGP-DI para janeiro de 2018.

Fonte: Elaboração própria com base nos dados do Banco Central do Brasil (2017a).

Gráfico 4 - Montante de recursos distribuídos pelo Pronaf entre as regiões brasileiras de 1999 a 2017

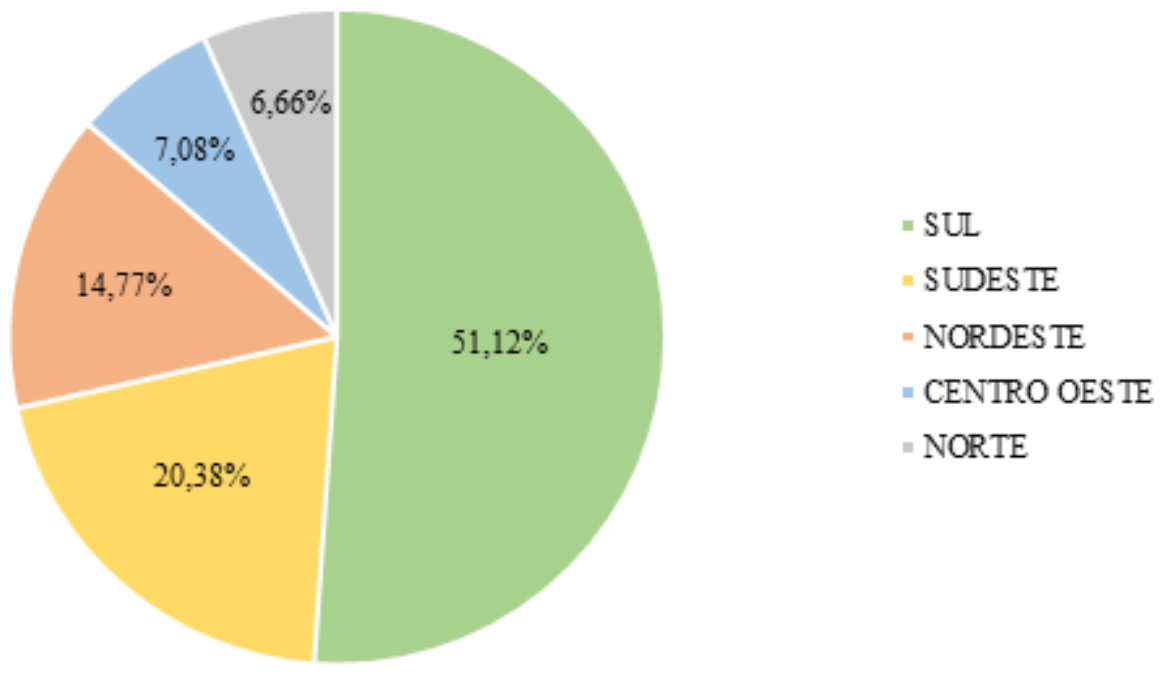

*Valores corrigidos pelo IGP-DI para janeiro de 2018.

Fonte: Elaboração própria com base nos dados do Banco Central do Brasil (2017a).

No primeiro ano de análise (1999), no Gráfico 3, a Região Sul concentrava 56,45\% do total de recursos liberados. Já a Região Norte, a menos beneficiada, recebeu 3,18\% do crédito total distribuído. Há redução desse percentual no ano de 2006, em que a Região Sul chega no patamar de $40 \%$ do total dos recursos distribuídos, porém volta a crescer nos anos seguintes, alcançando 54,37\% em 2008 e 56,98\% em 2017, último ano do período de análise. É difícil apontar qual é exatamente o problema causador da con- 
centração de crédito na Região Sul. Há indícios de que ela se dá pela forte presença de propriedades rurais de agricultores familiares já consolidados, aqueles que estão ligados às agroindústrias de suínos, aves, fumo e leite (MATTEI, 2015). Ainda, segundo Aquino e Schneider (2015), diferentes estudos ${ }^{7}$ buscaram evidenciar que a distribuição desigual dos recursos do Pronaf está associada a problemas operacionais e sociopolíticos, os quais não são competência do Programa. Nesse sentido, conforme os autores, entre os fatores relacionados às desigualdades socioespaciais, destacam-se: a) os obstáculos burocráticos impostos pelo sistema bancário aos agricultores familiares com níveis de renda inferiores; b) a organização dos agricultores mais capitalizados; c) as pressões de empresas agroindustriais às quais estes produtores estão vinculados; d) a concentração de agências bancárias e cooperativas de crédito nos Estados da Região Sul e e) a desarticulação e baixa inserção social dos produtores do Norte e do Nordeste.

As demais regiões praticamente desempenham um papel de figurantes quando comparadas com a Região Sul no montante de crédito distribuído. A Região Sudeste, segunda maior captadora de recursos provenientes do Pronaf (Gráfico 3), aparece com um montante de $\mathrm{R} \$ 1,4$ bilhão em 1999 , representando $17,76 \%$ do total de recursos distribuídos nesse ano. A região se destacou no ano de 2010, acumulando $R \$ 4,7$ bilhões, representando $24,31 \%$ do total distribuído. Nos anos seguintes volta declinar, chegando a representar $17,67 \%$ no ano de 2016 . A agricultura familiar presente na Região Sudeste possui um sistema de produção diversificado, os agricultores dessa região tendem a cultivar tanto culturas mais extensivas como o milho, que está vinculado ao contexto da especialização produtiva, como tendem a financiar culturas altamente exigentes em mão de obra, como o café, principalmente nos Estados de Minas Gerais e Espírito Santo (GRISA et al., 2014).

A Região Nordeste concentra mais de $50 \%$ dos estabelecimentos de base familiar do país. Nos anos de 2005 e 2006 chegou a concentrar 24,75\% e 26,01\% do total do crédito distribuído. Nos anos seguintes ocorre uma intensa redução na participação da região no montante total dos recursos disponibilizados, chegando no patamar de $10,96 \%$ em 2017 (AQUINO; SCHNEIDER, 2015; MATTEI, 2015). Caracterizada pelo baixo nível de renda da produção familiar, na região os agricultores familiares tendem a financiar a ampliação da escala daquilo que já produzem há muito tempo, dando pouca atenção à diversificação (MAGALHÃES; ABRAMOVAY, 2006).

As regiões Centro-Oeste e Norte possuem baixa participação na distribuição do crédito, com uma variação média anual entre 6,5\% a 7\% (GRISA et al., 2014). A participação máxima da Região Centro-Oeste foi em 2001, financiando R\$ 821 milhões do montante total distribuído, equivalente a 11\%. Já a Região Norte em 2014 obteve a maior participação, chegando a financiar mais $\mathrm{R} \$ 2,5$ bilhões do montante total distribuído, equivalente a $8,24 \%$. A agricultura familiar na Região Norte é marcada pelo meio

\footnotetext{
ABRAMOVAY, R.; VEIGA, J. E. Novas instituições para o desenvolvimento rural: o caso do Programa Nacional de Fortalecimento da Agricultura Familiar (Pronaf). Brasília: Ipea, 1999. (Texto para Discussão, 641).

BASTOS, F. Ambiente institucional no financiamento da agricultura familiar. São Paulo: Polis; Campinas: Ceres Centro de Estudos Rurais do IFCH - Unicamp, 2006.

SCHRÖDER, M.; SOUZA, I. C. de. Agricultores pobres e acesso ao Pronaf: a importância dos arranjos institucionais na intermediação da política pública. In: ENCONTRO ANUAL DA ASSOCIAÇÃO NACIONAL DE PÓSGRADUAÇÃO EM CIÊNCIAS SOCIAIS, ANPOCS, 2007, Caxambu. Anais [...]. Caxambu: Anpocs, 2007.
} 
ambiente amazônico, pelas dificuldades de comercialização, distância dos mercados consumidores e esgotamento da terra nas áreas de produção (LANDAU et al., 2013). As propriedades familiares da Região Norte e Região Nordeste são diferentes dos agricultores localizados na Região Sul, pois possuem uma agricultura menos mercantilizada e com menor emprego de tecnologia e, em alguns casos, de subsistência, somadas à saturação e ao desemprego nos centros urbanos. A Região Centro-Oeste, por sua vez, é reconhecida pelo seu caráter patronal, baseado na grande propriedade, com a utilização de tecnologia e insumos de ponta, e na plantation voltada para a exportação (GUILHOTO et al., 2007). O caráter patronal pode explicar, em parte, a baixa participação dessa região no montante de crédito distribuído.

O Gráfico 4 evidencia ainda a desigualdade nos repasses realizados pelo Pronaf entre as regiões brasileiras. No período entre 1999 e 2017 houve um repasse de R\$ 309 bilhões distribuídos entre as regiões brasileiras, e desse montante a Região Sul foi a maior beneficiária, financiando mais de $R \$ 158$ bilhões, equivalente a $51,12 \%$ do total de recursos liberados no período. A Região Sudeste, segunda maior beneficiária do Programa, financiou mais de $\mathrm{R} \$ 63$ bilhões, equivalente a 20,38\%; já a Região Nordeste financiou $R \$ 45$ bilhões, equivalente a 14,77\%; a Região Centro-Oeste financiou mais de $R \$ 21$ bilhões, equivalente a 7,08\%, e por fim, a Região Norte, a menos beneficiada, financiou mais de $R \$ 20$ bilhões, equivalente a $6,66 \%$.

Desse modo, percebe-se que historicamente a Região Sul foi a maior beneficiária do crédito do Pronaf, apresentando crescimentos de participação constantes em todos os anos do período de análise. O crédito nas regiões Nordeste e Sudeste teve leve crescimento. Já as Regiões Centro-Oeste e Norte é onde teve o menor crescimento do crédito no decorrer dos anos. Assim sendo, as distribuições regionais dos recursos do Pronaf encontram-se em um desequilíbrio que persiste desde 1999 até o ano de 2017.

Os resultados evidenciam que até 2006 o aumento de crédito na Região Nordeste é resultado da expansão do número de contratos, mas o valor dos financiamentos pode ser considerado baixo quando comparado com os contratos firmados pela Região Sul, entretanto a Região Nordeste aumentou a participação no total dos recursos, colaborando para a redução da desigualdade na distribuição dos financiamentos (AQUINO; SCHNEIDER, 2015). Desse modo, a análise empreendida neste artigo permite afirmar que até o ano de 2006 a redistribuição dos recursos visava a favorecer as regiões menos beneficiadas, promovendo a redução da desigualdade do crédito total distribuído.

Convém ressaltar que uma das explicações para a concentração do crédito rural no Brasil é de que ela existe onde estão localizados os agricultores familiares mais capitalizados, mais preparados e com maior auxílio do Estado (AQUINO; SCHNEIDER, 2015). Além disso, a política adotada pelo Pronaf é voltada para aqueles agricultores em fase de expansão, aqueles que apresentam potencialidades de serem transformados em empresas familiares, por intermédio da incorporação de tecnologia e de uma racionalidade econômica voltada para as demandas do mercado (CARNEIRO, 1997).

A partir dos dados apresentados, portanto, é possível afirmar que a busca por uma melhor distribuição regional do crédito deverá ser no sentido de reverter o quadro atual de desigualdades e condições das regiões brasileiras. Este cenário de desigualdade é fruto de todo o histórico de privilégios obtido por algumas regiões à custa do subdesenvolvimento de outras, além das questões tecnológicas e geográficas. 
Após a sucinta análise sobre os dados referentes ao valor financeiro total repassado pelo Programa Nacional de Fortalecimento da Agricultura Familiar entre as regiões brasileiras, será discutido no próximo tópico deste estudo a evolução das linhas de crédito, custeio e investimento, no período de 1999 a 2017.

\section{Evolução das Linhas de Crédito, Custeio e Investimento do Pronaf}

Todas as transformações ocorridas na estrutura do Pronaf somadas com o contexto macroeconômico brasileiro fizeram com que o número de contratos firmados entre as regiões brasileiras sofresse contínuas alterações no decorrer de 1999 a 2017. Até o ano de 2006 há uma expansão no número de contratos, em sua maior parte firmados pela Região Nordeste, que firmou mais de um milhão e meio de contratos, equivalente a $60,20 \%$ do total firmado no ano de 2006 . Nos anos seguintes houve redução dos contratos na Região Nordeste, chegando a representar apenas 37,74\% do total de contratos firmados em 2009 e isso elevou a participação das demais regiões nesse montante (BANCO..., 2017a).

Na distribuição regional de contratos a Região Sul esteve próxima da Região Nordeste em dois momentos distintos, em 2004 e em 2009. No ano de 2004, a Região Nordeste estava em sua fase de expansão de contratos, momento em que chegou a firmar mais de 530 mil, ultrapassando a Região Sul. Já em 2009, após um período de declínio da Região Nordeste, as regiões firmaram praticamente o mesmo número de contratos, chegando a representar 37,10\% a Região Sul e 37,80\% a Região Nordeste do total de contratos firmados no ano.

As regiões Sul e Nordeste presenciam uma realidade distinta e isso implica a quantia de contratos firmados e de crédito financiado. A principal diferença está na condição socioeconômica que cada uma delas apresenta: uma é caracterizada por unidades familiares capitalizadas e a outra por um vasto número unidades familiares pobres. Em contrapartida, a quantidade de contratos firmados pelas regiões não está associada ao perfil socioeconômico dos agricultores, e sim do montante de agricultores familiares localizados nelas; dessa forma, maior parte dos contratos firmados é destinado a regiões que contêm mais unidades familiares, como é o caso da Região Nordeste (MATTEI, 2015; AQUINO; SCHNEIDER, 2015; BIANCHINI, 2015).

As Regiões Nordeste e Sul são as que mais acessam contratos, com média contratual de 664 mil e 521 mil respectivamente; a Região Sudeste está com média contratual de 212 mil; as Regiões Norte e Centro-Oeste apresentaram média de contratos firmados bem abaixo das demais regiões, 67 mil e 48 mil contratos respectivamente. As três últimas regiões mencionadas tendem a se manter constantes em todo o período de análise, firmando praticamente o mesmo número de contratos, com poucas variações.

O modo de fortalecimento que o Programa Nacional de Fortalecimento da Agricultura Familiar gera nas regiões também pode ser avaliado com base nas suas modalidades de crédito que o Programa financia aos seus agricultores. O Gráfico 5 detalha o comportamento dessas linhas no período de 1999 a 2017, enquanto o Gráfico 6 apresenta o montante de crédito acumulado por meio da assinatura dos contratos realizados para custeio e investimento no período de 1999 a 2017. 
Gráfico 5 - Evolução das linhas de créditos, custeio e investimento de 1999 a 2017

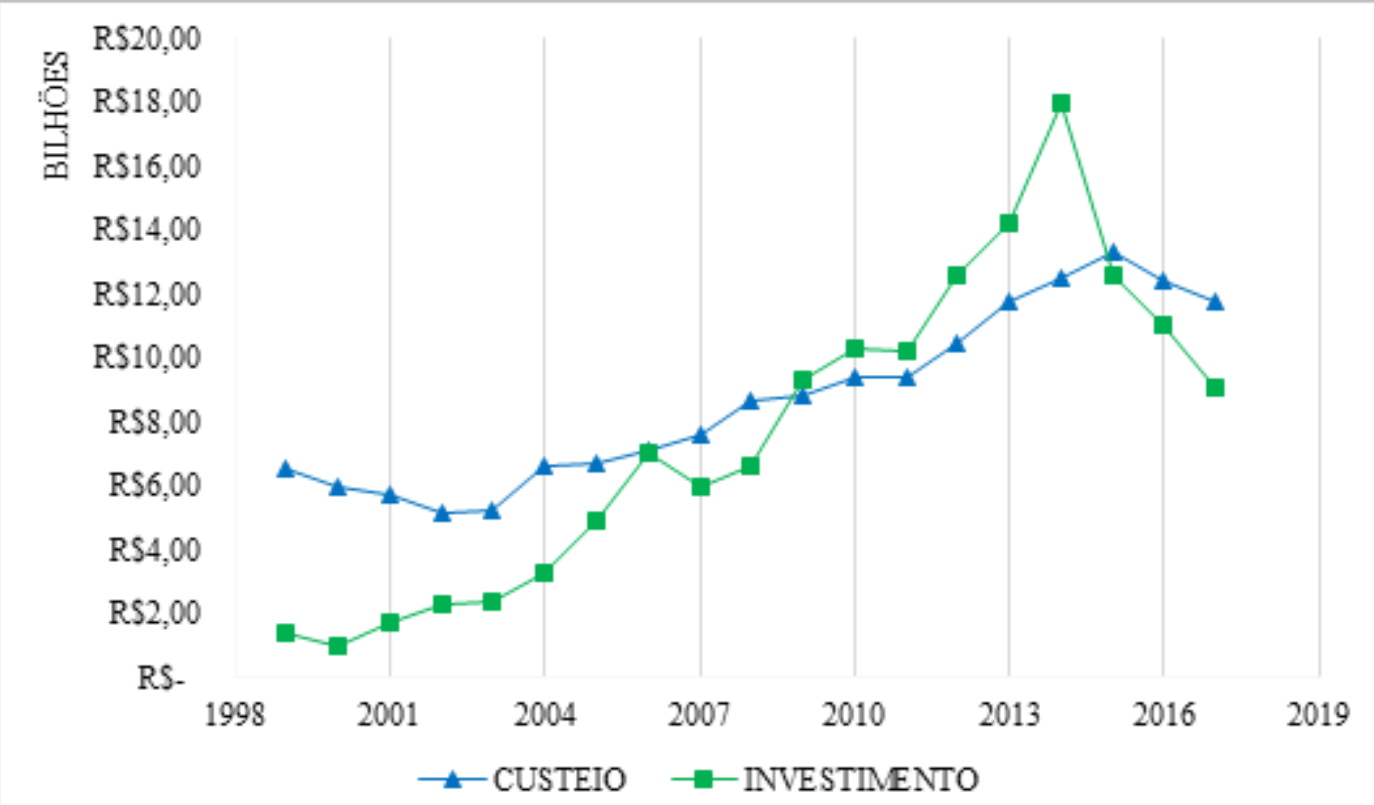

*Valores corrigidos pelo IGP-DI para janeiro de 2018.

Fonte: Elaboração própria com base nos dados do Banco Central do Brasil (2017a).

Gráfico 6 - Distribuição total de crédito custeio e investimento* do Pronaf entre as regiões brasileiras de 1999 a 2017

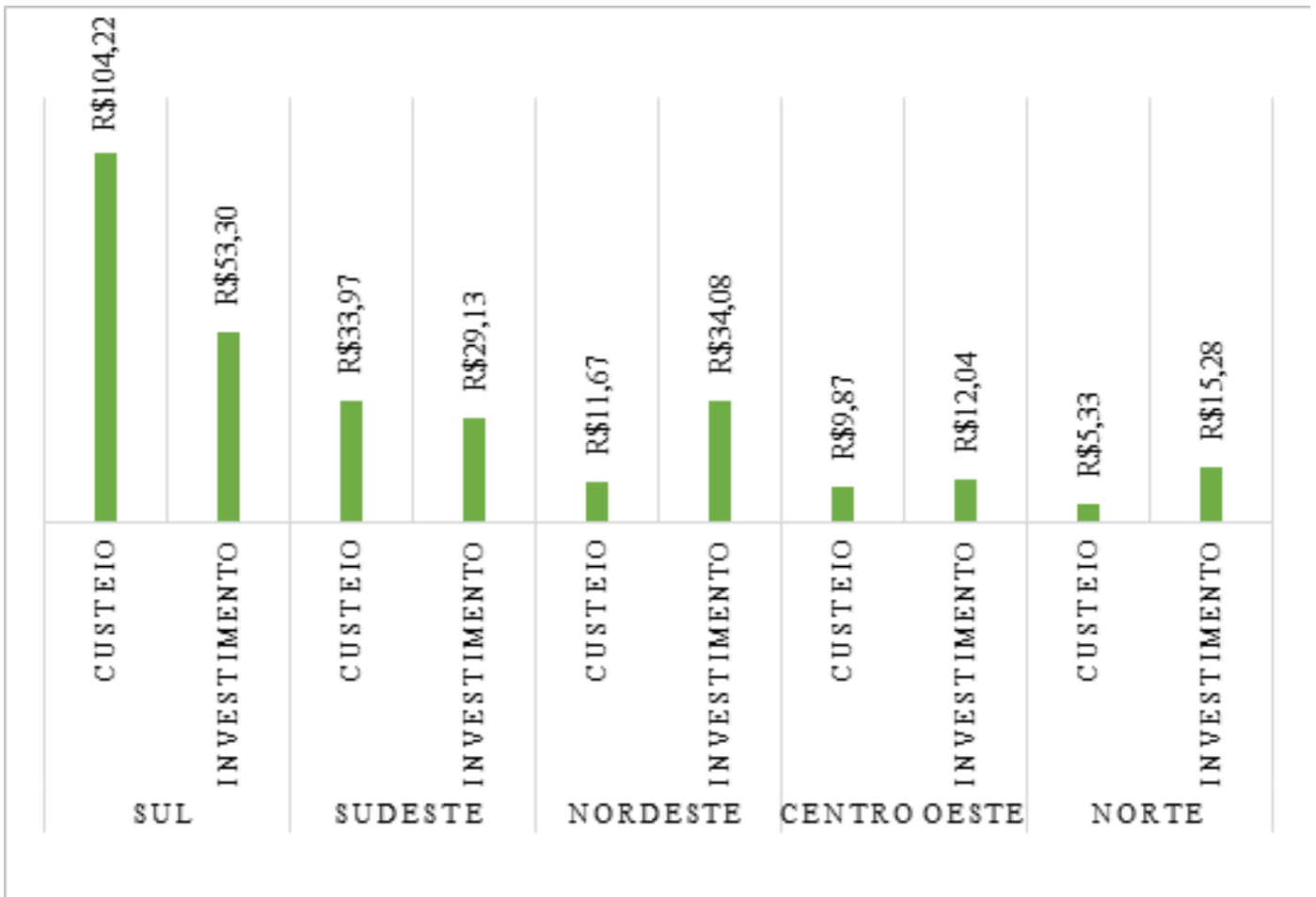

*Valores corrigidos pelo IGP-DI para janeiro de 2018.

Fonte: Elaboração própria com base nos dados do Banco Central do Brasil (2017a).

Em 1999 o crédito custeio respondia por 82,39\% (R\$ 6,5 bilhões), o crédito investimento correspondia a $17,61 \%$ ( $R \$ 1,3$ bilhão). 0 crédito de investimento esteve próximo do crédito custeio no ano de 2006, mas é apenas em 2007 que os créditos de 
investimento aumentaram consistentemente, chegando a ultrapassar o crédito custeio no ano de 2009, e prevalecendo até 2014. Aumentos no crédito de investimento estão relacionados ao melhoramento nas condições de oferta, tanto em termos dos custos financeiros dos recursos como dos prazos de pagamento (MATTEI, 2014a).

O crescimento expressivo do crédito de investimento ocorrido a partir de 2007 está vinculado ao tipo de política conduzida pelo presidente Luiz Inácio Lula da Silva para o enfrentamento da crise macroeconômica de 2008. A intenção do governo era criar um modo de incentivo ao crescimento da demanda doméstica por meio da expansão da oferta interna de alimentos básicos (MATTEI, 2014a). Há um declínio do crédito investimento a partir de 2014, ano em que este correspondia a 58,91\% ( $R \$ 17,9$ bilhões) e o crédito custeio $41,09 \%$ ( $R \$ 12,5$ bilhões). No último ano do período de análise, 0 crédito custeio respondia a $56,38 \%$, equivalente a $\mathrm{R} \$ 11,7$ bilhões, e o crédito de investimento respondia a 43,62\%, equivalente a $R \$ 9,09$ bilhões.

As Regiões Sul e Sudeste destinaram maior parte do crédito para o custeio de safra (Gráfico 6), 66,16\% e 53,84\% respectivamente. As regiões Nordeste, Centro-Oeste e Norte, menos beneficiadas pelo programa, destinaram a maior parte do crédito obtido para o investimento: $74,49 \%, 54,95 \%$ e $74,13 \%$ respectivamente.

O fato de as regiões mais capitalizadas destinarem a maior parte do crédito adquirido para o custeio de safra pode estar relacionado ao tipo de política promovida pelo Pronaf, o qual privilegia o financiamento de commodities agrícolas e o estímulo à especialização e não à diversificação de cultivos. Maior parte do crédito financiado pelas regiões capitalizadas tem sido destinado para fortalecer o modelo tradicional de progresso tecnológico e a especialização produtiva (AQUINO; SCHNEIDER, 2015).

Diante do que foi exposto, compreende-se que a agricultura familiar não se encontra distribuída de maneira uniforme entre as regiões brasileiras, portanto a desigualdade analisada no número de contratos firmados poderia, presumivelmente, estar relacionada a essa desuniformidade. Desse modo, a Região Nordeste, caracterizada por possuir um vasto número de unidades familiares pobres, cresceu e tornou-se a líder em contratos firmados devido à ampliação do programa no amparo a agricultores mais pobres (MATTEI et al., 2007; BIANCHINI, 2015; AQUINO; SCHNEIDER, 2015; MATTEI, 2015).

No que diz respeito às linhas custeio e investimento, pode-se notar que as regiões mais capitalizadas, como as Regiões Sul e Sudeste, destinaram maior parte do crédito para o custeio de safra. Já nas regiões que não exercem um protagonismo no programa, ou seja, naquelas menos beneficiadas, como as regiões Nordeste, Centro-Oeste e Norte, foi possível observar que elas tendem a destinar maior parte do crédito obtido para o investimento. Desse modo, pode-se afirmar que a condição socioeconômica e as características de produção das regiões somadas com o contexto macroeconômico influenciam no tipo de crédito acessado.

Após ser apresentada a evolução das linhas de créditos custeio e investimento do Programa Nacional de Fortalecimento da Agricultura Familiar, a próxima seção irá expor os principais problemas, limitações e desafios a serem superados pelo programa. 


\section{Entraves e Desafios do Pronaf}

Uma política pública, fruto de construção participativa entre o Movimento Social Organizado e o governo, o Programa Nacional de Fortalecimento da Agricultura Familiar, em seus 23 anos de vigência, obteve ótimos resultados no amparo ao agricultor familiar. De acordo com Aquino e Schneider (2015), porém, seu histórico é marcado por avanços e ambiguidades, pois nem todas as modificações que foram inseridas ao longo da atuação do Programa resultaram em uma política que beneficiasse corretamente todos os segmentos presentes no contexto do setor de produção familiar brasileiro.

De acordo com Mattei (2015), o Programa Nacional de Fortalecimento da Agricultura Familiar não modificou significativamente a lógica prevalecente no modelo agrícola brasileiro, pois segue financiando e promovendo a agricultura moderna, principalmente a produção de commodities agropecuárias. Além disso, na Região Sul, a maior beneficiária do programa, a atuação do Pronaf foi voltada ao fortalecimento do modelo de agricultura embasado na utilização de insumos modernos e na produção de commodities agrícolas orientadas ao mercado internacional.

Além disso, os produtores de commodities são exatamente os clientes preferidos dos bancos, aqueles capazes de oferecer garantias de pagamento. Já a parte empobrecida dos agricultores do país não é capaz nem de acessar ou manter um vínculo constante com o sistema bancário brasileiro devido ao perfil socioeconômico e o tipo de produção (AQUINO; SCHENEIDER, 2015).

Nesse mesmo sentido, Mattei (2015) complementa que a instrumentalização financeira do Pronaf permanece adotando o mesmo formato do sistema clássico do crédito rural, tornando-o dependente das preferências dos agentes financeiros. Percebe-se, portanto, que não houve grandes alterações ao longo do tempo, uma vez que os bancos permanecem operando para o atendimento dos seus clientes preferenciais, 0 que bloqueia e restringe a entrada de diversas modalidades de crédito que beneficiam diferentes segmentos de agricultores familiares.

Apesar de reconhecida importância social e econômica, cabe destacar as limitações do Pronaf, que também indicam desafios para os governantes no sentido de meIhorar o Programa. Estes aspectos são relatados no Quadro 3.

Quadro 3 - Síntese dos principais entraves e desafios enfrentados pelo Programa Nacional de Fortalecimento da Agricultura Familiar

\begin{tabular}{|c|c|}
\hline Entraves & Desafios \\
\hline Concentração de crédito da Região Sul. & $\begin{array}{c}\text { Diminuir a desigualdade da distribuição do crédito. } \\
\text { Procurar métodos não excludentes no auxílio a pequena } \\
\text { propriedade. }\end{array}$ \\
$\begin{array}{c}\text { Beneficiar agricultores modernos e capita- } \\
\text { lizados, produtores de commodities. }\end{array}$ & $\begin{array}{c}\text { Adaptar o programa à pluralidade regional dos agriculto- } \\
\text { res familiares em suas diferentes realidades. } \\
\text { Promover em maior magnitude a diversificação da produ- } \\
\text { ção e das fontes de rendimento. } \\
\text { Seletividade bancária. }\end{array}$ \\
$\begin{array}{c}\text { Extinguir a prática seletiva dos bancos e beneficiar os di- } \\
\text { versos segmentos de agricultores familiares. }\end{array}$ \\
\hline
\end{tabular}

Fonte: Elaboração própria com base na literatura de Grisa et al., (2014); Carneiro (1997); Mattei (2015); Gazolla e Schneider (2013); Aquino e Schneider (2015); Bianchini (2015). 
O Quadro 3 apresenta uma síntese dos principais entraves e desafios enfrentados pelo Pronaf. A partir de estudos e pesquisas realizados ao longo destes pouco mais de 20 anos de atuação do Programa, percebe-se que ele apresenta concentração do crédito em regiões tidas como mais desenvolvidas e tem sido acessado por agricultores capitalizados, integrados ao mercado - produtores de commodities agrícolas. Além disso, tem-se como entrave para o melhor desempenho do Programa a seletividade bancária, no entanto, apesar dos entraves e desafios mencionados, reconhece-se a importância do Programa Nacional de Fortalecimento da Agricultura familiar para o desenvolvimento rural brasileiro. O Programa constitui-se como um avanço das políticas públicas voltadas para a agricultura, sobretudo por ter foco na agricultura de cunho familiar.

Após a exposição dos principais entraves e desafios enfrentados pelo Programa Nacional de Fortalecimento da Agricultura Familiar, serão apresentadas, na próxima seção, as considerações finais realizadas em relação à problemática proposta pelo presente estudo.

\section{CONSIDERAÇÕES FINAIS}

Analisando a trajetória do Programa Nacional de Fortalecimento da Agricultura Familiar é possível concluir que a política é um importante instrumento de apoio à agricultura familiar. O Pronaf é acompanhado de desigualdade e concentração na distribuição do crédito, uma vez que entre 1999 e 2002 a distribuição dos recursos estava concentrada na Região Sul. Posteriormente, os recursos foram mais bem distribuídos no período entre 2003 e 2006, momento em que as regiões Nordeste, Sudeste e Norte, as menos beneficiadas pelo crédito do Programa, expandiram o número de contratos. Esse aumento de contratos possibilitou a expansão da participação das regiões Nordeste, Sudeste e Norte no montante total de crédito distribuído, além de contribuir com a redução da desigualdade, uma vez que o aumento da participação dessas regiões provocou a queda do percentual da Região Sul.

Embora a distribuição dos recursos tenha melhorado, a partir de 2007 tem-se a reconcentração dos recursos na Região Sul novamente, mantendo-se e acentuando-se nos anos finais da série. Essa reversão explica-se pela diminuição dos contratos firmados pela Região Nordeste e pelo fato de o Programa voltar a promover e beneficiar a agricultura moderna, voltada para agricultores produtores de commodities agropecuárias localizados em regiões capitalizadas.

Verificou-se que regiões capitalizadas como as Regiões Sul e Sudeste destinaram maior parte do crédito para o custeio de safra, já nas regiões menos beneficiadas, como as regiões Nordeste, Centro-Oeste e Norte, foi possível observar que elas tendem a destinar maior parte do crédito obtido para o investimento. $O$ fato de as regiões mais capitalizadas destinarem a maior parte do crédito adquirido para o custeio de safra explica-se pelo tipo de política que vem sendo promovida pelo Pronaf, que privilegia o financiamento de commodities agrícolas e o estímulo à especialização e não à diversificação de cultivos. Dessa maneira, a maior parte do crédito financiado pelas regiões capitalizadas tem sido destinado para fortalecer o modelo tradicional de progresso tecnológico e a especialização produtiva. 
Atualmente, o principal entrave do Pronaf é a opção por beneficiar agricultores capitalizados produtores de commodities, seguindo o mesmo caminho do Sistema Nacional do Crédito Rural. Foi constatado que o Programa não está promovendo a diversificação econômica, e isso deixa os beneficiários sujeitos à variabilidade climática e à volatilidade dos preços. Desse modo, diante do que foi exposto neste estudo, cabe refletir sobre a atuação de um programa que foi pensado para priorizar e fomentar a diversidade de atividades agrícolas dos agricultores familiares. Nesse mesmo sentido, convém questionar se a deficiência está no Pronaf ou nas outras políticas agrícolas e assistência técnica, além das universidades, que incentivam a produção para exportação.

Sendo assim, diante dessa trajetória constata-se que o Pronaf ainda não descobriu sua estrutura ideal. Faz-se necessária uma reformulação do Programa, de modo que incentive os agricultores familiares menos capitalizados e menos integrados ao mercado a buscarem o crédito. $O$ baixo acesso de unidades familiares pobres é problema que ainda persiste.

A própria heterogeneidade da agricultura familiar faz com que as políticas públicas voltadas para a categoria tenham dificuldades de serem adequadas. Precisam ao mesmo tempo: a) serem amplas para atenderem toda a diversidade de unidades de produção; b) estimular e desenvolver a agricultura familiar com menos capital e integração no mercado; c) sem deixar de viabilizar aquelas propriedades já capitalizadas e inseridas nos mercados, especialmente pelas especificidades da produção agropecuária. Esse impasse dificulta o Programa em manter foco e cumprir com as regras propostas na sua criação. Flexibilidade passa a ser imperativo do Pronaf para atender à heterogeneidade da categoria.

Ao mesmo tempo que se reconhece a importância do Pronaf dentro da economia brasileira, principal instrumento de apoio aos agricultores familiares, também se defende a necessidade de reformulação no sentido de atender a todas as regiões e todos os beneficiários de forma homogênea. Complementar a isso, quem gerencia o Programa deve reconhecer que o crédito por si só não é suficiente para alavancar regiões mais pobres. Ações nos âmbitos econômico, social e cultural devem ser coordenadas nessas regiões, entretanto o quadro atual do Programa tende a se manter o mesmo, pelo fato de atualmente não haver clima político e econômico dentro do governo federal para que transforme/reformule o futuro dessa política.

\section{REFERÊNCIAS}

AQUINO, J. R. Avanços e limites da política de crédito do Pronaf no Brasil (1996-2008): uma reflexão crítica. In: CONGRESSO DA SOCIEDADE BRASILEIRA DE ECONOMIA, ADMINISTRAÇÃO E SOCIOLOGIA RURAL, 47., 2009, Porto Alegre. Anais [...]. Porto Alegre, RS, 2009.

AQUINO, J. R; SCHNEIDER, S. O Pronaf e o desenvolvimento rural brasileiro: avanços, contradições e desafios para o futuro. In: GRISA, C.; SCHNEIDER, S. (org.). Políticas de desenvolvimento rural no Brasil. Porto Alegre: UFRGS, 2015.

BANCO CENTRAL DO BRASIL. Crédito rural. Brasília: Bacen, 2017a. Disponível em: http://www.bcb.gov.br/ pt-br\#!/n/credrural. Acesso em: 12 abr. 2017.

BANCO CENTRAL DO BRASIL. Glossário. IGP-DI. Brasília: Bacen, 2017b. Disponível em: https://www.bcb. gov.br/glossario.asp?Definicao=999\&idioma=P\&idpai=GLOSSARIO. Acesso em: 14 ago. 2017.

BIANCHINI, V. Vinte anos do Pronaf, 1995-2015: avanços e desafios. Brasília: SAF; MDA, 2015.

BRASIL. Decreto n. 1.946, de 28 de junho de 1996. Cria o Pronaf e dá outras providências. Disponível em: http://www.planalto.gov.br/ccivil_03/decreto/D1946.htm. Acesso em: 3 jun. 2017. 
BRASIL. Resolução n. 2629, de 10 de agosto de 1999. Altera e consolida as normas aplicáveis aos financiamentos rurais ao amparo do Pronaf. Disponível em: http://www.bcb.gov.br/pre/normativos/res/1999/ pdf/res_2629_v2_L.pdf. Acesso em: 2 set. 2017.

BRASIL. Resolução n. 3.206, de 24 de junho de 2004. Dispõe sobre alterações no regulamento do Pronaf. Disponível em: https://www.bcb.gov.br/pre/normativos/busca/

downloadNormativo.asp?arquivo=/Lists/Normativos/Attachments/46387/Res_3206_v2_L.pdf. Acesso em: 5 set. 2017.

BRASIL. Lei n. 11.326, de 24 de julho de 2006. Estabelece as diretrizes para a formulação da Política Nacional da Agricultura Familiar e Empreendimentos Familiares Rurais. Disponível em: http://www.planalto. gov.br/ccivil_03/_ato2004-2006/2006/lei/l11326.htm. Acesso em: 25 maio 2017.

BRASIL. Portaria n. 234, de 4 de abril de 2017. Estabelece o regulamento e as condições para a realização das operações de crédito rural ao amparo do Pronaf. Diário Oficial da União, Brasília, DF, 2017. Disponível em: http://www.mda.gov.br/sitemda/sites/sitemda/

files/user_img_1754/PORTARIA\%20N\%C2\%BA\%20234\%2C\%20DE\%2004\%20DE\%20ABRIL\%20DE\%20 2017.pdf. Acesso em: 15 jun. 2017.

BRUMER, A. et al. A exploração familiar no Brasil. In: LAMARCHE, H. (coord.). Agricultura familiar: comparação internacional. Campinas: Editora da Unicamp, 1997. p. 179-234.

BUAINAIN, M. A.; ROMEIRO, A. R.; GUANZIROLI, C. Agricultura familiar e o novo mundo rural. Sociologias, Porto Alegre, ano 5. n. 10, jul./dez. 2003.

CARMO, R. B. A. A questão agrária e o perfil da agricultura familiar brasileira. Bahia Agrícola, Bahia, v. 4, p. 27-32, 2000.

CARNEIRO M. J. Política pública e agricultura familiar: uma leitura do Pronaf. Estudos Sociedade e Agricultura, Rio de Janeiro: UFRRJ, v. 1, n. 8, abr. 1997.

CONTI, B. M.; ROITMAN, F. B. Pronaf: uma análise da evolução das fontes de recursos utilizadas no programa. Revista do BNDES, n. 35, p. 131-168, jun. 2011.

COSTA, C. R.; SIMIONATTO, I. O Pronaf no Governo Lula e a Proteção do Estado aos Interesses do Agronegócio. In: JORNADA INTERNACIONAL DE POLÍTICAS PÚBLICAS, 4., 2013, São Luiz. Anais [...]. São Luiz, Maranhão, Brasil, 2013.

DEL GROSSI, M. E.; SILVA, J. F. G. Novo rural: uma abordagem ilustrada. Londrina: Instituto Agronômico do Paraná (lapar), 2002.

GAZOLLA, M.; SCHNEIDER, S. Qual? Fortalecimento? Da Agricultura Familiar? Uma análise do Pronaf crédito de custeio e investimento no Rio Grande do Sul. Revista de Economia e Sociologia Rural (Impresso), v. 51, p. 45-68, 2013.

GERHARDT, T. E.; SILVEIRA, D. T. (org.). Métodos de pesquisa. Porto Alegre: Editora da UFRGS, 2009.

GIL, A. C. Métodos e técnicas de pesquisa social. 6. ed. São Paulo: Atlas, 2012.

GRISA, C.; SCHNEIDER, S. Três gerações de políticas públicas para a agricultura familiar e formas de interação entre sociedade e Estado no Brasil. Revista de Economia e Sociologia Rural, Piracicaba, v. 52, n. 1, p. 125-146, 2014.

GRISA, C. et al. Revisitando o Pronaf: velhos questionamentos, novas interpretações. Revista de Economia e Sociologia Rural (Impresso), v. 52, p. 323-346, 2014.

GUANZIROLI, C. E. Pronaf dez anos depois: resultados e perspectivas para o desenvolvimento rural. Revista de Economia e Sociologia Rural, Brasília, v. 45, n. 2, p. 301-328, abr./jun. 2007.

GUANZIROLI, C.; CARDIM, S. E. (coord.). Novo retrato da agricultura familiar: o Brasil redescoberto. Brasília: Projeto de Cooperação Técnica FAO/Incra, fev. 2000.

GUILHOTO, J. et al. A importância da agricultura familiar no Brasil e em seus Estados. In: ENCONTRO NACIONAL DE ECONOMIA, 35., 2007, Recife. Anais [...]. Recife, de 4 a 7 de dezembro 2007.

HAIR JR., J. F. et al. Fundamentos de métodos de pesquisa em administração. Porto Alegre: Bookman, 2005.

LANDAU, E. C et al. Concentração geográfica da agricultura familiar no Brasil. Série Documentos, Embrapa Milho e Sorgo, v. 155, p. 1-66, 2013.

LAMARCHE, E. A agricultura familiar: comparação internacional. 2. ed. Campinas: Unicamp, 1997.

MAGALHÃES, R.; ABRAMOVAY, R. Acesso, uso e sustentabilidade do Pronaf B. São Paulo: MDA; Fipe, 2006. $25 p$.

MATTEI, L. Impactos do Pronaf: análise de indicadores. Brasília: MDA; Nead, 2005.

MATTEI, L. Evolução do crédito do Pronaf para as categorias de agricultores familiares A e A/C entre 2000 e 2010. Revista Econômica do Nordeste, v. 45, p. 58-69, 2014a. 
MATTEI, L. O papel e a importância da agricultura familiar no desenvolvimento rural brasileiro contemporâneo. Revista Econômica do Nordeste, v. 45, p. 71-79, 2014b.

MATTEI, L. Políticas públicas de apoio à agricultura familiar: o caso recente do Pronaf no Brasil. Raízes, UFPB, v. 35, p. 1-15, 2015.

MATTEI, L. et al. Uma análise dos impactos do Pronaf sobre as economias locais nas regiões Nordeste, Sudeste e Norte do Brasil. In: CONGRESSO DA SOCIEDADE BRASILEIRA DE ECONOMIA, ADMINISTRAÇÃO E SOCIOLOGIA RURAL, 45., 2007. Anais [...]. Londrina, 22 a 25 de julho, 2007.

MDA. Plano Safra da Agricultura Familiar 2017/2020. Brasília, DF, 2017. Disponível em: www.mda.gov.br/ sitemda/sites/sitemda/files/user_img_1684/3Baixa_Cartilha_Plano_Safra_2017.pdf. Acesso em: 27 ago. 2017.

PAULA, L. F.; PIRES, M. Crise e perspectivas para a economia brasileira. Revista: Estudos Avançados, Rio de Janeiro, v. 31, n. 89, p. 125-144, 2017.

SAVOLDI, A.; CUNHA, L. A. G. Uma abordagem sobre agricultura familiar, Pronaf e a modernização da agricultura no sudoeste do Paraná na década de 1970. Revista Geografar, Curitiba, v. 5, n. 1, p. 25-45, jan./ jun. 2010.

SCHNEIDER, S. Teoria social, agricultura familiar e pluriatividade. Revista Brasileira de Ciências Sociais, São Paulo, v. 18, n. 51, p. 99-121, 2003.

SCHNEIDER, S. Agricultura familiar e desenvolvimento rural endógeno: elementos teóricos e um estudo de caso. In: FROEHLICH, J. M.; VIVIEN D. (org). Desenvolvimento rural: tendências e debates contemporâneos. Ijuí: Ed. Unijuí, 2006.

SCHNEIDER, S. et al. F. Histórico, caracterização e dinâmica recente do Pronaf - Programa Nacional de Fortalecimento da Agricultura Familiar. In: SCHNEIDER, S.; SILVA, M. K.; MARQUES, P. E. M. (org.). Políticas públicas e participação social no Brasil rural. Porto Alegre: Editora da UFRGS, 2004.

SCHNEIDER, S.; CASSOL, A. P. Diversidade e heterogeneidade da agricultura familiar no Brasil e algumas implicações para políticas públicas. Cadernos de Ciência \& Tecnologia, v. 31, p. 227-263, 2014.

WANDERLEY, M. N. B. Raízes históricas do campesinato brasileiro. In: ENCONTRO ANUAL DA ANPOCS, 20., 1996, Caxambu. Anais [...]. Minas Gerais, de 22 a 26 de outubro de 1996.

WOLLENHAUPT, S. Metodologia científica: notas introdutórias. Porto Alegre: Razão Bureau Editorial, 2004. 